\title{
Position of the Embolized Atrial Septal Defect Device Matters in Retrieval and Safe Outcome
}

\author{
Reena Nebu ${ }^{1}$, Renu L Upadhyay ${ }^{2}$, Sanjeeta R Umbarkar ${ }^{3}$, Manjula S Sarkar $^{4}$
}

\begin{abstract}
Percutaneous device closure of atrial septal defect (ASD) is an alternative to traditional surgical closure. Various advantages of percutaneous correction are less invasive, early recovery, less hospital stay. Yet the complications such as arrhythmia, cardiac tamponade, and device embolization cannot be ignored. We report a case of ASD device embolization in case of ostium secondum ASD with deficient aortic rim. The embolized device was stuck in the main pulmonary artery at bifurcation in the vertical position, which required surgical intervention for retrieval. Keywords: Amplatzer septal occluder, Aortic rim, Atrial septal defect, Device embolization, Main pulmonary artery. Research and Innovation in Anesthesia (2019): 10.5005/jp-journals-10049-0063
\end{abstract}

\section{INTRODUCTION}

Atrial septal defect (ASD) is one of the most common types of congenital heart defects, with $25 \%$ incidence. It encompasses defects involving both the true septal membrane and other defects that allow for communication between both atria. There are five types of ASDs: Patent foramen ovale, ostium secundum (OS) defect, ostium primum defect, sinus venosus defect, and coronary sinus defect. Small ASDs usually spontaneously close in childhood. Large defects that do not close spontaneously may require percutaneous or surgical intervention to prevent further complications such as stroke, dysrhythmias, and pulmonary hypertension. ${ }^{1}$ Although percutaneous intervention has high rate of success and safety, ASD closure device embolization can occur leading to fatal complication even death. It is noted in $0.3-0.6 \%$ of cases. $^{2}$

\section{Case Description}

A 17-year-old female presented with $\mathrm{C} / \mathrm{O}$ abdominal pain since 1 year and diagnosed with polycystic ovarian disease (PCOD). During investigation with contrast-enhanced CT (CECT), the right heart strain pattern and congestive hepatomegaly were noticed. ECG was s/o normal sinus rhythm, $T$ inversion in $\mathrm{V} 4-5$, right axis deviation. After which 2D echo revealed congenital heart disease (CHD), OS ASD of $20 \mathrm{~mm}$ with deficient aortic and IVC rim, and leftto-right shunt. Transesophageal echocardiography (TEE) was done to confirm suitability of OS ASD device closure (DC).

Patient was posted for ASD DC in the cath lab. While loading the Amplatzer septal occluder device, the cardiologist faced difficulty and was successful after three attempts under fluoroscopy and TEE guidance. Device placement was done over ASD but immediately the device got detached and embolized. On fluoroscopy, the device was localized to be in the main pulmonary artery. For emergency retrieval of the embolized ASD device, the patient was shifted to the cardiac operation theater from the cath lab in a hemodynamically stable condition. Central venous access and radial artery cannulation were done in the cath lab in view of (I/V/O) emergency situation.

After shifting to OT, standard and invasive monitors were attached. The patient was maintained on volume control ventilation (VCV) with $\mathrm{O}_{2}$ /air/sevoflurane with $\mathrm{FiO}_{2}$ 0.5. On intraoperative TEE,
${ }^{1}$ Department of Cardiovascular and Thoracic Surgery Anesthesia, Seth Gordhandas Sunderdas Medical College, Mumbai, Maharashtra, India ${ }^{2}$ Department of Cardiovascular and Thoracic Surgery, King Edward Memorial Hospital, Mumbai, Maharashtra, India

${ }^{3}$ Department of Anaesthesiology, King Edward Memorial Hospital and Seth Gordhandas Sunderdas Medical College, Mumbai, Maharashtra, India

${ }^{4}$ Department of Cardiac Anesthesia, King Edward Memorial Hospital and Seth Gordhandas Sunderdas Medical College, Mumbai, Maharashtra, India

Corresponding Author: Reena Nebu, Department of Cardiovascular and Thoracic Surgery Anesthesia, Seth Gordhandas Sunderdas Medical College, Mumbai, Maharashtra, India, Phone: +91 9820024211 , e-mail: reenanebu@rediffmail.com

How to cite this article: Nebu R, Upadhyay RL, Umbarkar SR, et al. Position of the Embolized Atrial Septal Defect Device Matters in Retrieval and Safe Outcome. Res Inno in Anesth 2019;4(1):21-22.

Source of support: Nil

Conflict of interest: None

device location was confirmed in the pulmonary artery and ASD noted.

Standard midline sternotomy and pericardiotomy were done. After adequate heparinization and confirming the activated clotting time (ACT) level, aortobicaval cannulation was followed with aortic clamping and cardioplegia was given. Right atriotomy was done and ASD of around $2 \times 2 \mathrm{~cm}$ size was seen. The main pulmonary artery was opened and the device was recovered (Fig. 1). Atrial septal defect was repaired with a pericardial patch. Rewarming was started and right atriotomy closure was done. After de-airing, the aortic cross clamp was removed. The patient came out of bypass uneventfully and reversed with protamine and confirmed with the normalized ACT level. Arterial blood gas (ABG) was within normal limit pre-retrieval and post-retrieval after coming off bypass.

The patient was shifted to the ICU. Extubation was done after 4 hours, and the patient was shifted to the ward on 3rd day after removing intercostals drains and ambulation. The patient was discharged on 5th day. 


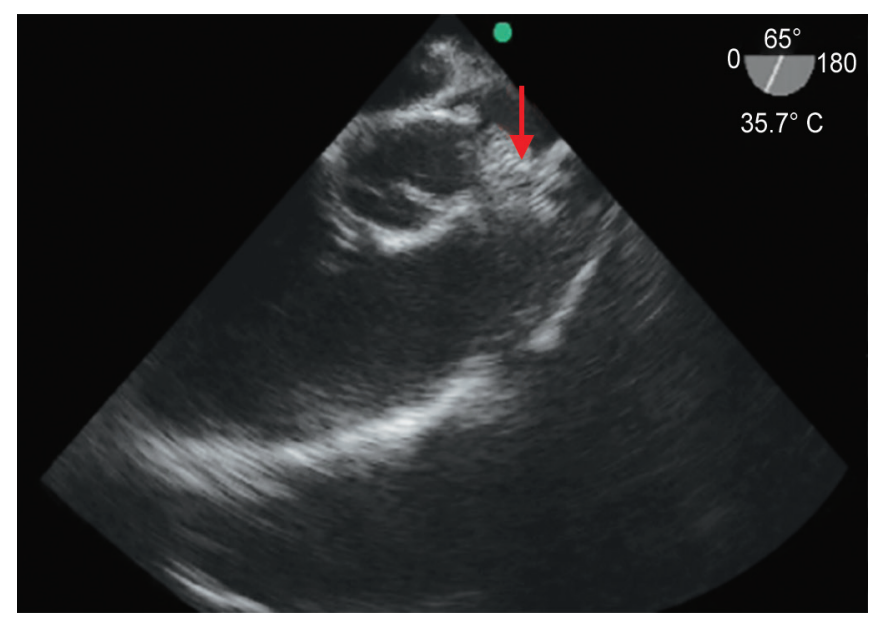

Fig. 1: Intraoperative transesophageal echocardiography view showing embolized device in main pulmonary artery

\section{Discussion}

Ostium secundum ASD device closure was introduced in 1974 by King and Mills with a Dacron polyester fabric-covered steel umbrella, as an alternative to surgical closure. Success rate of the Amplatzer septal occluder is around $95-98 \% .^{3}$ Complications associated are arrhythmia, cardiac tamponade, and device embolization occurring immediately or in later period. In a survey of the Amplatzer septal occluder (ASO) company-designated proctors, the incidence of ASO embolization in this group's experience was $0.55 \%$ ( 21 embolizations in 3,824 device placements) with a wide range of patient demographics, ASD sizes, and device sizes. ${ }^{4}$ Device embolization is one of the life-threatening complications requiring immediate removal via percutaneous or the surgical method. Device embolization can occur because of small right atrium, large ASD, deficient aortic rim (less than $5 \mathrm{~mm}$ ), 3,5 undersizing of device, technical difficulty, and operator skill. ${ }^{2}$

In our case, it was technical difficulty in loading Amplatzer device and deficient aortic rim. It took three attempts for the cardiologist to load the device that finally was placed over ASD but immediately got embolized. On fluoroscopy in the cath lab and TEE done in OT, the embolized device was noticed in the pulmonary artery at bifurcation more of in the vertical position. So, the flow was maintained and the patient was hemodynamically stable.
This could have resulted in a fatal outcome if the device would have been lodged in the horizontal position. It could have led to pulmonary artery obstruction or hemorrhage. ${ }^{3}$

\section{Conclusion}

The preprocedural evaluation of ASD size and rim character should be followed as per the selection criteria. Transesophageal echocardiography can be used as an informative tool in the preprocedural as well as the intraprocedural period. ${ }^{6}$ In case of device-related complications, prompt decision and timely action are warranted, which requires multidisciplinary management between cardiologists, cardiac surgeons, cardiac anesthetists, and perfusionists.

\section{ACKNOWLedgments}

We are grateful to Dr Hemant Deshmukh (dean sir) for permitting us to publish this case report. We are also thankful to the CVTS Department, Cardiologists and Cardiovascular Thoracic Anesthesia colleagues who have helped us in successful management of this case and writing this case report.

\section{References}

1. Celermajer DS. Atrial septal defects: even simple congenital heart diseases can be complicated. Eur Heart J 2018;39(12):999-1001. DOI: 10.1093/eurheartj/ehx633.

2. Hamur $\mathrm{H}$, Onk OA, Degirmenci $\mathrm{H}$, et al. The retrieval of atrial septal defect closure device embolised into aortic arch. Intractable Rare Dis Res 2016;5(2):114-116. DOI: 10.5582/irdr.2016.01016.

3. Son JW, Park JS. Subacute, silent embolization of amplatzer atrial septal defect closure device to the pulmonary artery. J Cardiovasc Ultrasound 2012;20:201-204. DOI: 10.4250/jcu.2012.20.4.201.

4. Levi DS, Moore JW. Embolization and retrieval of the Amplatzer septal occluder. Catheter Cardiovasc Interv 2004;61:543-547. DOI: 10.1002/ ccd.20011.

5. Misra M, Sadiq A, Namboodiri N, et al. The 'aortic rim' recount: embolization of interatrial septal occluder into the main pulmonary artery bifurcation after atrial septal defect closure. Interact Cardiovasc Thorac Surg 2007;6(3):384-386. DOI: 10.1510/icvts.2006.141044.

6. Lin SM, Tsai SK, Wang JK, et al. Supplementing transesophageal echocardiography with transthoracic echocardiography for monitoring transcatheter closure of atrial septal defects with attenuated anterior rim: a case series. Anesth Analg 2003;96(6):15841588. DOI: 10.1213/01.ANE.0000062651.59656.B4. 